\title{
Overexpression of Ets-1 in human hematopoietic progenitor cells blocks erythroid and promotes megakaryocytic differentiation
}

\author{
V Lulli ${ }^{1}$, P Romania ${ }^{1}$, O Morsilli ${ }^{1}$ M Gabbianelli ${ }^{1}$, A Pagliuca ${ }^{1}$, \\ S Mazzeo ${ }^{1}$, U Testa ${ }^{1}$, C Peschle ${ }^{1,2}$ and G Marziali, \\ 1 Department of Hematology, Oncology and Molecular Medicine, Istituto \\ Superiore di Sanità, 00161 Rome, Italy \\ 2 Kimmel Cancer Institute, T. Jefferson University, Philadelphia, PA 19107- \\ 5541, USA \\ * Corresponding author: G Marziali, Department of Hematology, Oncology and \\ Molecular Medicine, Istituto Superiore di Sanità, Regina Elena 299, 00161 \\ Rome, Italy. Tel: + 39-06-49902781; Fax + 39-06-49387087; \\ E-mail: marziali@iss.it
}

Received 16.5.05; revised 04.10.05; accepted 10.10.05; published online 18.11.05 Edited by $G$ Ciliberto

\begin{abstract}
Ets-1 is a widely expressed transcription factor implicated in development, tumorigenesis and hematopoiesis. We analyzed Ets-1 gene expression during human erythroid and megakaryocytic (MK) differentiation in unilineage cultures of $\mathrm{CD}_{3} 4^{+}$progenitor cells. During erythroid maturation, Ets-1 is downmodulated and exported from the nucleus into the cytoplasm through an active mechanism mediated by a leucine-rich nuclear export signal. In contrast, during megakaryocytopoiesis Ets-1 increases and remains localized in the nucleus up to terminal maturation. Overexpression of Ets-1 in erythroid cells blocks maturation at the polychromatophilic stage, increases GATA-2 and decreases both GATA-1 and erythropoietin receptor expression. Conversely, Ets-1 overexpressing megakaryocytes are characterized by enhanced differentiation and maturation, coupled with upmodulation of GATA-2 and megakaryocyte-specific genes. We show that Ets-1 binds to and activates the GATA-2 promoter, in vitro and in vivo, indicating that one of the pathways through which Ets-1 blocks erythroid and promotes MK differentiation is via upmodulation of GATA-2 expression.
\end{abstract}

Cell Death and Differentiation (2006) 13, 1064-1074.

doi:10.1038/sj.cdd.4401811; published online 18 November 2005

Keywords: transcription factors; subcellular localization; nuclear export signal; GATA-2; Ets binding sites

Abbreviations: HPCs, hematopoietic progenitor cells; NES, nuclear export signal; NLS, nuclear localization signal; CRM1/ exportin1, chromosome region maintenance1/exportin1; FLC, Friend erythroleukemia cells; GFP, green fluorescent protein; RT$P C R$, reverse transcriptase polymerase chain reaction; $E$, erythroid; MK, megakaryocytic; EBS, ets binding site; LMB, leptomycin B; IRES, internal ribosome entry site

\section{Introduction}

The Ets family of transcription factors is characterized by the presence of a highly conserved winged helix-turn-helix DNA binding domain. Through this domain the Ets proteins bind to specific purine-rich DNA sequences containing a conserved GGA core ${ }^{1}$ and regulate a wide range of biological processes, such as embryogenesis, differentiation and oncogenesis. ${ }^{2,3}$ Ets-1 is the founding member of this gene family and was initially identified as the proto-oncogene corresponding to the v-Ets oncogene of the E26 leukemia virus. Several post-translational modifications regulate the function of Ets1 protein. These include intramolecular inhibition of DNA binding, ${ }^{4}$ phosphorylation-dependent inhibition of DNA binding, ${ }^{5}$ phosphorylation and activation of transactivation domain $^{6}$ and protein-protein interaction. ${ }^{2,3}$ During embryonic development Ets-1 is expressed in a variety of mesoderm derived tissues and in endothelial cells during vasculogenesis and angiogenesis. ${ }^{7}$ In the hematopoietic system Ets-1 is involved in the regulation of lymphopoiesis ${ }^{8}$ and the development of natural killer cells. ${ }^{9}$ Despite extensive studies on Ets-1, its role in myeloid hematopoietic cells is still largely unexplored. In erythropoiesis it is debated whether Ets-1 acts as a positive regulator ${ }^{10,11}$ or as an inhibitor of erythroid differentiation. ${ }^{12,13}$ In megakaryocytopoiesis Ets-1 is upregulated $^{14}$ and, Ets binding sites (EBS) have been identified in many megakaryocyte-specific gene promoters. ${ }^{15}$ Only few studies, however, have examined its specific role in megakaryocytic (MK) differentiation.

Hematopoiesis is a complex process regulated by sets of transcription factors in a stage-specific and context-dependent manner. During erythropoiesis, determination of cell fate depends on the ability to repress survival/proliferation transcription factors (i.e. PU.1, GATA-2), and to express prodifferentiation genes at developmental crossroads. Both erythroid and MK lineages are derived from a common bipotential progenitor and share many lineage-restricted transcription factors including GATA-2. GATA-2 is a key transcription factor in controlling cell fate outcome within the stem and early progenitor cell compartments and plays an important role in hematopoietic commitment. ${ }^{16,17}$ GATA-2 null mice are embryonic lethal due to severe anemia during the early phase of yolk sac hematopoiesis (E10/11) and GATA-2 -/- embryonic stem cells failed to contribute to all hematopoietic lineages in chimeric mice. ${ }^{16,18}$ Several data suggest that the levels of GATA-2 expression determine in part the fate along megakaryocyte-erythroid differentiation pathway. ${ }^{19-22}$ During erythropoiesis GATA proteins switch from GATA-2, in early progenitors, to GATA-1 in terminally differentiating cells therefore linking GATA-2 downregulation to terminal erythroid maturation. ${ }^{19-21}$ On the contrary, GATA2 is expressed at high levels during MK differentiation, ${ }^{14}$ suggesting a relevant role of GATA-2 also during terminal 
thrombopoiesis. ${ }^{22}$ However, despite the pivotal role played by GATA-2 during hematopoiesis, the mechanisms controlling its expression are still largely unexplored.

We previously showed that Ets-1 overexpression in Friend erythroleukemia cell (FLC) and K562 erythroid cell lines blocks erythroid maturation. ${ }^{23}$ In this study, we showed that during human erythroid progenitor cell differentiation, Ets-1 is downmodulated and actively exported from the nucleus to the cytoplasm via a chromosome region maintenance1/exportin1 (CRM1/exportin1)-dependent pathway. CRM1/exportin1 is a nuclear export receptor which translocates proteins containing a leucine-rich nuclear export signal (NES) to the cytoplasmic compartment. ${ }^{24}$ We identified a functional NES within the pointed domain of the protein able to drive Ets-1 nuclear export during erythroid maturation. Conversely, during all stages of MK differentiation Ets-1 remains localized in the nucleus. We furthermore show that Ets-1 binds to and activates the GATA-2 promoter in vitro and in vivo, indicating that Ets-1 directly and positively regulates GATA-2 expression. Thus, GATA-2 upmodulation could mediate, at least in part, the opposite effects of Ets-1 on erythroid and MK differentiation. Altogether, our results demonstrate that Ets-1 positively controls the MK differentiation pathway, while its downregulation is required for terminal erythroid maturation.

\section{Results}

\section{Ets-1 is expressed throughout MK differentiation and is downregulated during erythroid maturation}

We initially determined the expression of Ets-1 during HPC unilineage erythroid and MK differentiation. Ets-1 mRNA levels were evaluated by semiquantitative reverse transcriptase polymerase chain reaction (RT-PCR); starting from quiescent $\mathrm{CD}^{+} 4^{+}$cells, total RNA was extracted from erythroid and MK cells, at different days of culture until their complete differentiation. A representative experiment for each culture condition is shown in Figure 1. During erythroid (E) differentiation Ets-1 expression was detectable from quiescent hematopoietic progenitor cells (HPCs) up to day 9 of culture corresponding to the basophilic stage of erythroblast differentiation. Ets-1 mRNA was undetectable starting from day 10 of culture when the cells proceed to terminal maturation moving to polychromatophilic (days 10-12) and orthochromatic erythroblasts (days 13-14) (Figure 1a). Conversely, Ets-1 mRNA did not decrease during MK differentiation until late stages of maturation (Figure 1b).

\section{Ets-1 subcellular localization changes along erythroid differentiation}

We next analyzed the pattern of Ets-1 protein expression by confocal microscopy of immunostained cells (Figure 2a). In undifferentiated HPCs (d0), Ets-1 reactivity was mainly confined to the nucleus. During the maturation process, the protein changed its subcellular localization and was detected in both compartments until the polychromatophilic stage. At later stages of erythroid differentiation, Ets-1 reactivity was observed only within the cytoplasm (Figure 2a). Double staining experiments of erythroid cells (day 11), with anti-
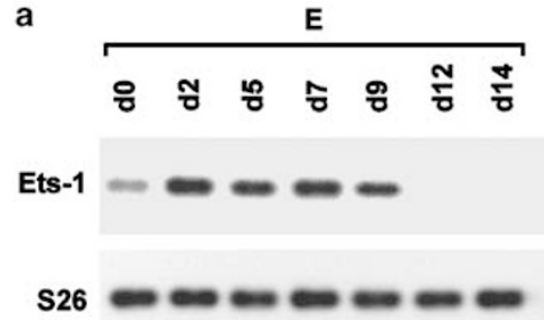

b
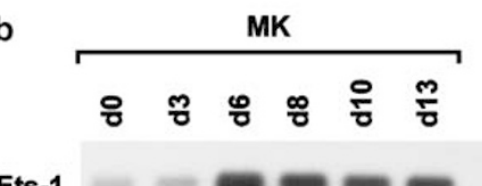

S26

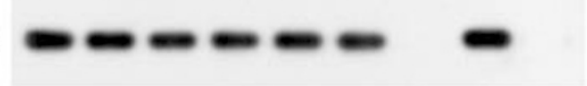

Figure 1 Ets-1 mRNA expression during erythroid and megakaryocytic (MK) HPCs differentiation. (a, b) Semiquantitative RT-PCR analysis of Ets-1 mRNA in HPC liquid suspension cultures induced to unilineage erythroid $(E)$ or MK differentiation at different days of culture. A representative experiment of three independent experiments is shown. S26 was used for normalization and K562 erythroleukemia cell line was the internal positive control

Ets-1 and anti-GATA-1 antibodies, showed that Ets-1 antibody labels the cytoplasm ring, whereas GATA-1 antibody labels the nucleus (Figure $2 b$ ).

The pattern of Ets-1 subcellular localization was confirmed by Western blot analysis (Figure 2c). In undifferentiated HPCs, Ets-1 protein was detected only inside the nuclear compartment. During early stages of erythroid differentiation Ets-1 was localized both in the cytoplasm and in the nucleus. However, when erythroid cells moved to terminal maturation stages, the level of Ets-1 decreased in the nucleus, almost completely disappearing in polychromatophilic erythroblasts (day 11). A different subcellular localization of Ets-1 was observed during MK differentiation. Confocal microscopy (Figure $3 a$ ) and Western blot analysis (Figure $3 b$ ) revealed that Ets-1 was detectable both in the nucleus and the cytoplasm in all MK maturation stages. Double staining experiments of MK cells with anti-Ets- 1 and anti-GATA-1, showed that both proteins co-localized inside the nucleus (Figure 3a). These results suggested that both nuclear exclusion and decreased expression of Ets-1 represent crucial events in terminal erythroid differentiation, whereas high levels of nuclear Ets-1 are required throughout MK maturation.

\section{Ets-1 nuclear exclusion involves a NES}

Several proteins containing the Rev-like NES are exported from the nucleus through the CRM1/exportin1 pathway. Leptomycin B (LMB) is a specific inhibitor of the NESdependent CRM1/exportin1 receptor and can be used to block nuclear export. ${ }^{24}$ We asked if the progressive cytoplasmic localization of Ets-1, during erythroid differentiation, was based on the onset of a LMB-sensitive nuclear export. As shown in Figure $4 \mathrm{a}$ and $\mathrm{b}$, after LMB treatment (250 nM for $4 \mathrm{~h}$ ) 
a
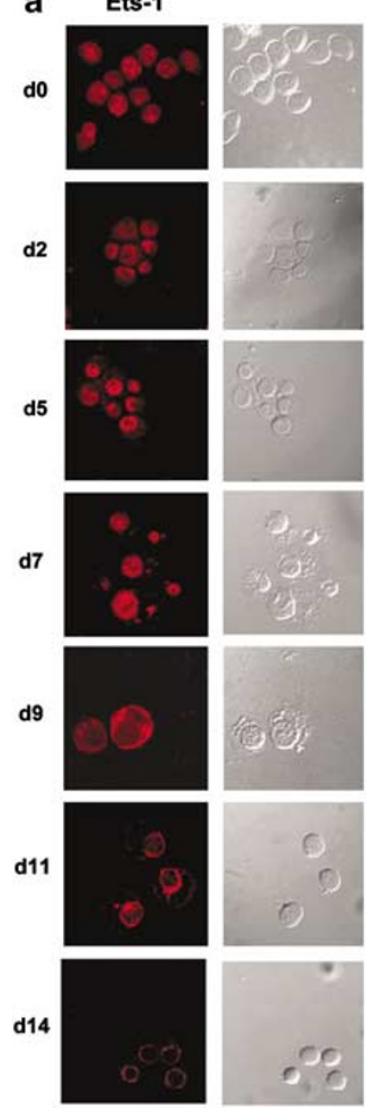

Figure 2 Nuclear-cytoplasmic translocation of Ets-1 during erythroid differentiation. (a) Localization of Ets-1 in HPCs differentiating along the erythroid lineage at different days of culture. In the right panel is shown the cell morphology by interphase microscopy; the left panel represents the confocal microscopy of the same cells, stained with anti Ets-1 antibody (red, rhodamine). (b) Confocal microscopy of day $11 \mathrm{E}$ cells analyzed by interphase contrast (top, left quadrant), stained with anti-GATA-1 (green, FITC, top right quadrant) or antiEts-1 (red, rhodamine, bottom quadrant), or both anti-GATA-1 and anti-Ets-1 antibodies (bottom, right quadrant). Original magnification $\times 630$. (c) Ets-1 protein level was evaluated by Western blot analysis of cytoplasmic and nuclear extracts at different days of erythroid differentiation. Immunoblotting with actin, nucleolin and $\alpha$-tubulin (not shown) antibodies was performed to verify equal loading, enrichment and nuclear cytoplasmic contamination of cytosolic and nuclear fractions. The figure show typical results obtained from three different experiments

of erythroid cells (day 11, polychromatophilic erythroblasts), Ets-1 protein relocalized mainly to the cell nucleus.

By examining the sequence of Ets-1, we found two aminoacid stretches that perfectly matched the leucine-rich NES consensus sequence. The first stretch, located within the ets domain (amino-acids 336-345), was previously shown to be unable to mediate nuclear export. ${ }^{25}$ The other putative NES was located within the pointed domain between amino-acids 121 and 131 (Figure 4c). To analyze if this sequence could mediate Ets-1 export, a cDNA fragment corresponding to amino-acids 87-156 was fused to the green fluorescent protein (GFP) reporter linked to a nuclear localization signal (NLS). The fusion protein was expressed in FLC cells, which are erythroid precursors blocked in their differentiation pathway at the proerythroblastic stage and can be induced to terminal erythroid differentiation by DMSO. As controls a
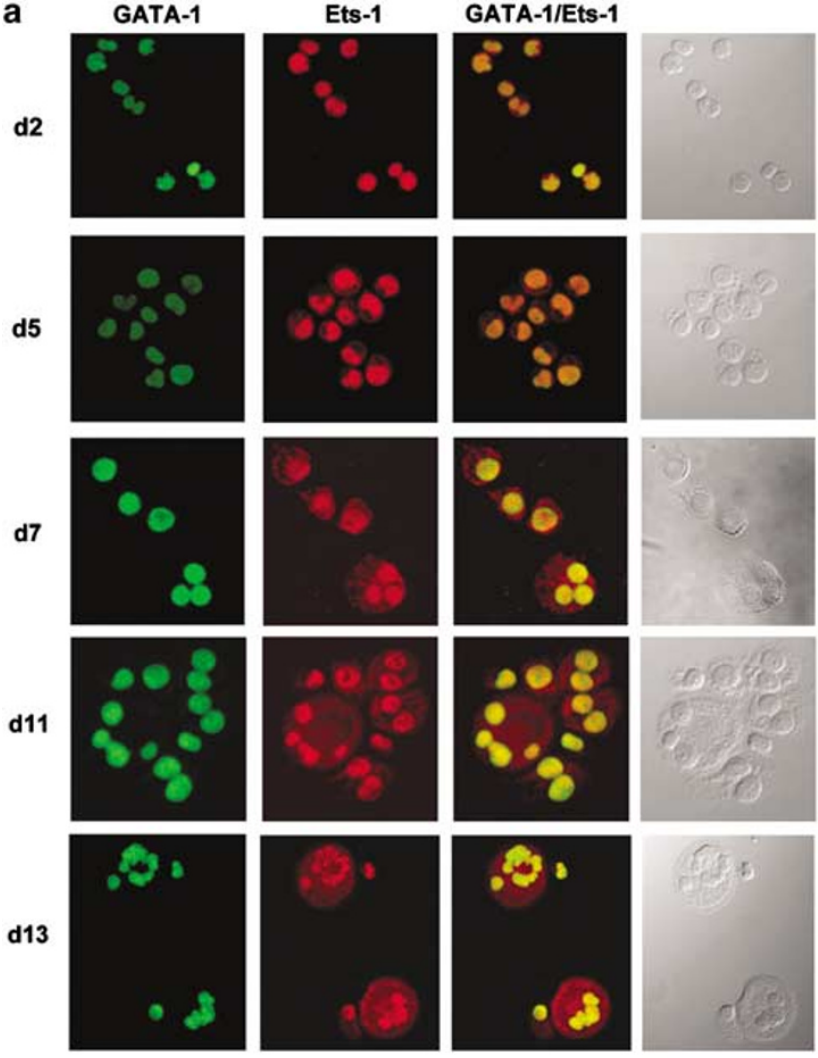

d11
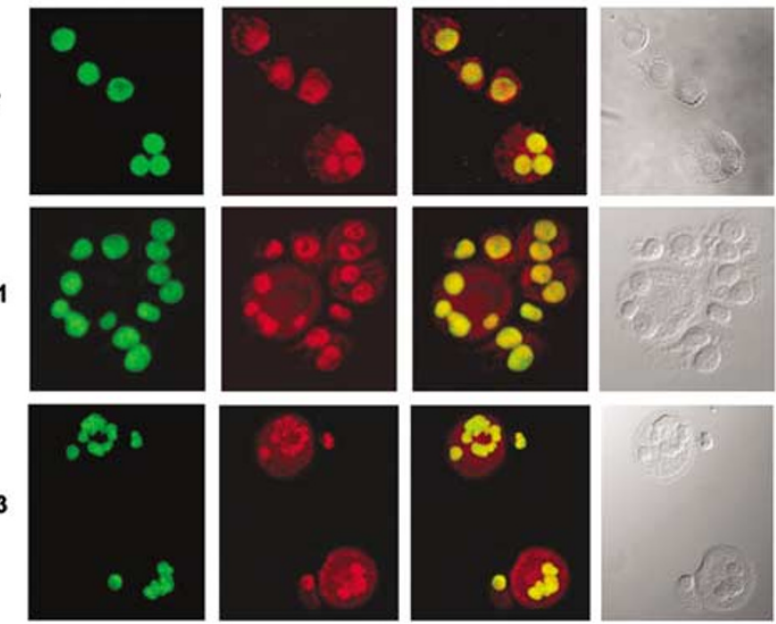

b

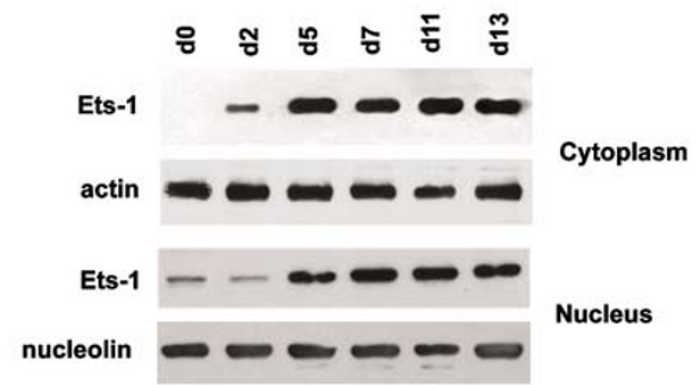

Figure 3 Ets-1 subcellular localization during MK maturation. (a) Ets-1 subcellular localization analyzed by confocal fluorescence microscopy (original magnification $\times 630$ ) at different days of culture and $(\mathbf{b})$ by Western blot analysis. Representative experiments of three independent experiments are shown

$2 \times$ GFP-NLS-NES-Rev and a $2 \times$ GFP-NLS constructs were used. The subcellular localization of these constructs in the presence or absence of LMB was then analyzed by confocal microscopy. As shown in Figure 4d (top), the $2 \times$ GFP-NLS protein was found only inside the nucleus, whereas the $2 \times$ GFP-NLS-NES-Rev control fusion protein was uniformly distributed between cytoplasm and nucleus. The $2 \times$ GFPNLS-NES-Ets- 1 fusion behaved as the $2 \times$ GFP-NLS-NESRev being equally distributed in the cytoplasm and the nucleus indicating that the Ets-1 region corresponding to amino-acids 87-156 is sufficient to mediate nuclear export. As shown in Figure $4 \mathrm{~d}$ (bottom) after $4 \mathrm{~h}$ of LMB treatment the nuclear export of GFP was inhibited and nuclear accumulation was induced. To confirm that the hydrophobic sequence corresponding to amino-acids $121-131$ is critical for Ets-1 nuclear export, a mutant containing two amino-acid 
a

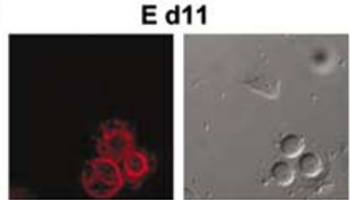

E d11+LMB

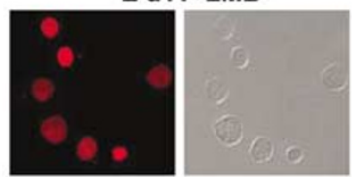

c
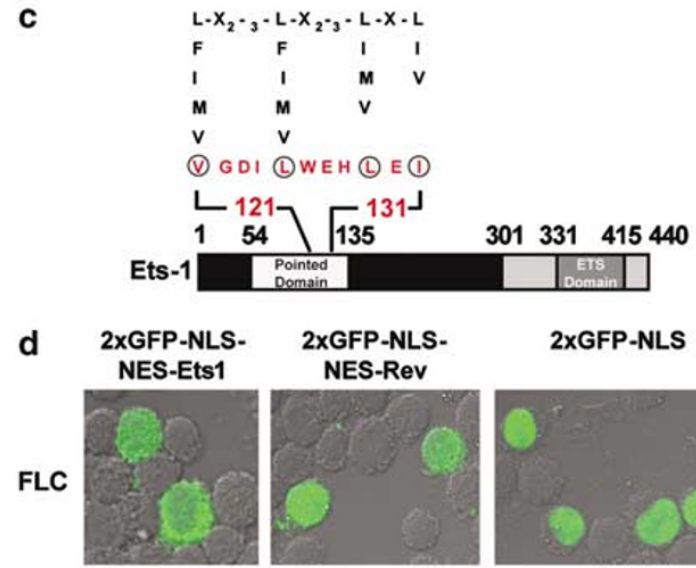

2XGFP-NLSNES-Rev
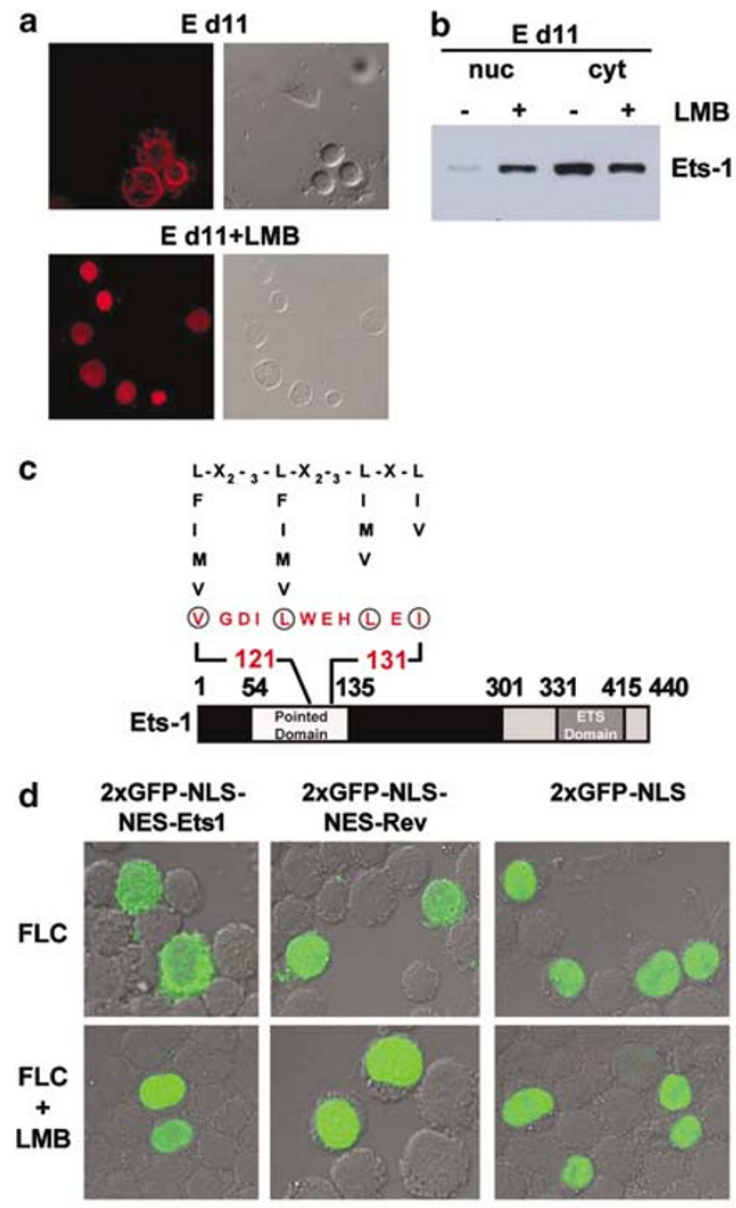

e

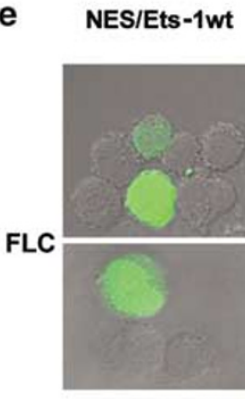

Ets-1wt-GFP
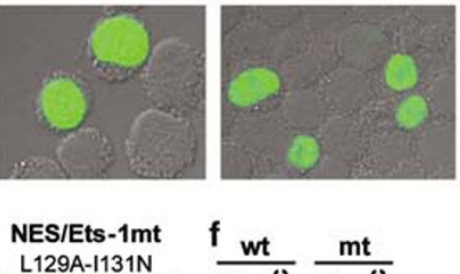

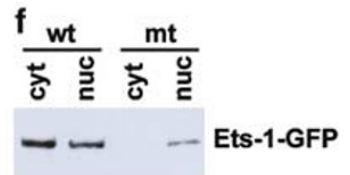

Figure 4 Ets-1 NES mediates nuclear export in erythroid cells. (a) Ets-1 subcellular localization in erythroid cells treated or not with LMB was analyzed by confocal fluorescence microscopy (original magnification $\times 630$ ) and $(b)$ by Western Blot analysis. (c) Schematic representation of Ets-1 protein and alignment of the NES of Ets-1 with the NES consensus sequence. (d) A $2 \times$ GFP construct fused to NES sequences from either Ets-1 or HIV-Rev and a $2 \times$ GFP construct containing only the NLS, were transfected in differentiating FLC cells. Localization of GFP was determined in the presence or absence of LMB. (e) (Top) Localization of the mutated $2 \times$ GFP-NLS-NES-Ets-1 (L129A, I131N) construct with respect to $2 \times$ GFP-NLS-NES-Ets- 1 wild-type and (bottom) localization of the full-length Ets-1-GFP fusion protein with mutations in the NES with respect to wild-type protein. Mutations Leu129 to alanine and lle131 to asparagine were made within the full Ets-1 protein fused to GFP and expressed in FLC cells. (f) Western Blot analysis of FLCs transiently transfected either with the full-length mutated NES Ets-1-GFP fusion protein or wild-type Ets-1-GFP. Cytoplasmic and nuclear cell extracts were run on SDS-PAGE and probed with anti GFP-antibody

substitutions (L129A, I131N) was constructed. The activity of the Ets-1/NES (L129A, I131N) was completely ablated indicating that hydrophobic amino acids at positions 129 and 131 are critical for nuclear export (Figure 4e, top).

For more detailed analysis we evaluated the behavior of the entire Ets-1 protein containing the amino-acid substitutions L129A and I131N fused to the GFP reporter gene. The subcellular localization of Ets-1 (L129A, I131N)-GFP and wildtype Ets-1-GFP was evaluated following transfection of FLCs either by confocal microscopy and by Western Blot analysis (Figure $4 \mathrm{e}$, bottom, and f). The mutant fusion protein was localized only inside the nuclear compartment, indicating that the 121-131 Ets-1 region is both necessary and sufficient to mediate Ets-1 export to the cytoplasm. These results demonstrate that the progressive nuclear exclusion of Ets-1 during erythroid differentiation is based on an active export mechanism mediated by a functional NES located within the pointed domain of the protein.

\section{Enforced expression of Ets- 1 in CD34 ${ }^{+}$ hematopoietic cells blocks erythroid and triggers MK differentiation}

Our results suggested that nuclear exclusion and the downregulation of Ets-1 are important in the commitment to terminal erythroid differentiation, whereas maintenance of high levels of Ets-1 are necessary during MK maturation. To further investigate the role of Ets-1, during normal erythroid and MK differentiation, a bicistronic retroviral vector Pinco $(\mathrm{Pi})$ (Figure 5a) was used to obtain enforced expression of Ets-1 in $\mathrm{CD} 4^{+}$cells purified from human peripheral blood (PB). In this type of vector, Ets-1 cDNA is transcriptionally linked to the GFP gene by a viral internal ribosome entry site (IRES). Purified $\mathrm{CD} 34^{+}$were initially triggered to cycle using 'cycling HGFs' (i.e. KL, IL-3, FL, bFGF and IL-6), to increase the efficiency of infection without triggering differentiation. After this initial cell cycling period $\mathrm{CD} 34^{+}$cells were infected with either PilRES-GFP/Ets-1 or the control retroviral (PilRESGFP) supernatants. After transduction, the cells efficiently expressing GFP were selected by fluorescence-activated cell sorting (FACS) and grown either in erythroid or MK unilineage culture to drive their selective differentiation.

At different days of culture total RNA was extracted from control and Ets-1 transduced cells and Ets-1 overexpression was assessed by semiquantitative RT-PCR. Evaluation by densitometry and normalization based on S26 band intensity ensured a semiquantitative measure of mRNA levels in both subsets. In both lineages a strong overexpression of Ets-1 mRNA was observed only in cells transduced with PilRESGFP/Ets-1 (Figures 5d and 6c) even with a low number of amplification cycles.

Evaluation of erythroid proliferation rate provided evidence that Ets-1 overexpressing cells proliferate at a lower rate compared to cells transduced with PilRES-GFP (Figure 5b). Analysis of the morphology at different days of culture showed that erythroid maturation is blocked at the polychromatophilic stage in Ets-1 overexpressing cells (Figure 5c).

We also analyzed whether Ets-1 overexpression resulted in any modulation of genes involved in erythroid maturation such 

5' LTR

3' LTR

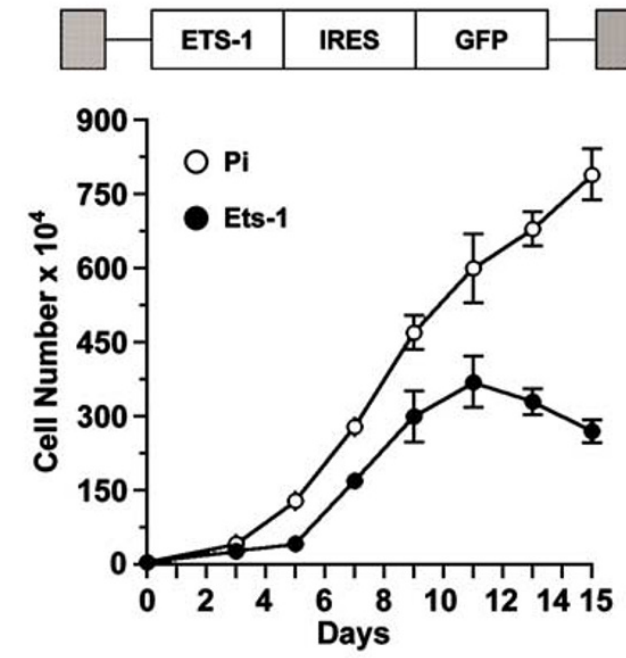

b

C

d5 d7
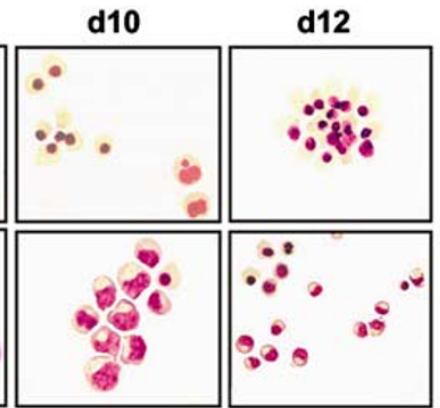

d

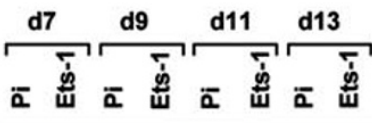

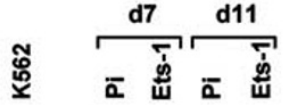

ชัญํํ

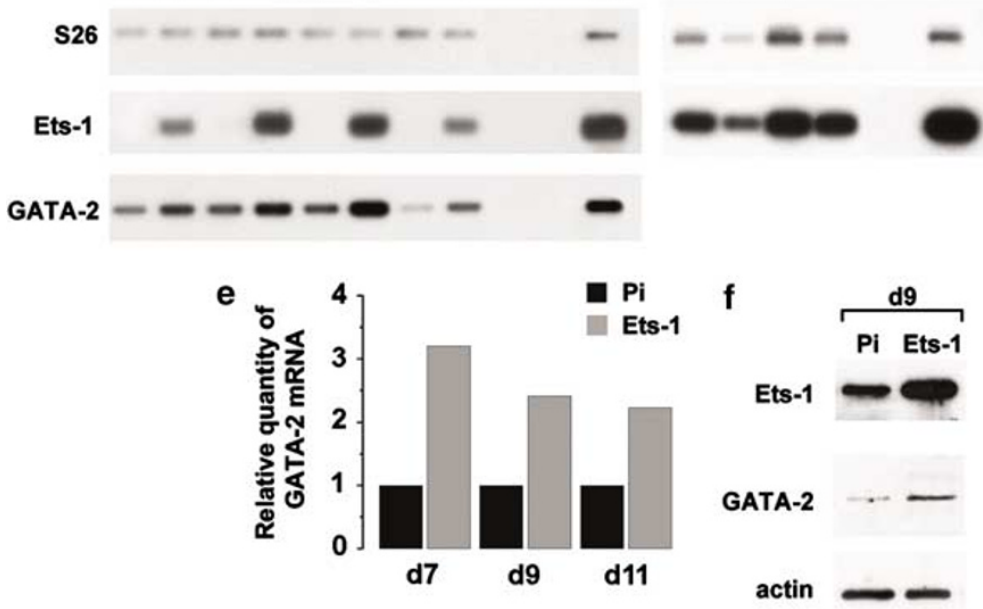

Figure 5 Effects of Ets-1 overexpression on erythroid differentiation. (a) Pinco-IRES-GFP/ Ets-1 vector. The transfer vector contains the full-length Moloney LTR and a cassette composed of Ets-1-IRES-GFP (b) Growth curves and (c) representative morphology (bottom, original magnification $\times 630$ ) of unilineage erythroid culture from HPCs transduced with PilRES-GFP (Pi) or PilRES-GFP/Ets-1 (Ets-1). Mean \pm S.E.M. values are representative of three independent experiments. (d) Semiquantitative RT-PCR analysis of Ets-1, GATA-2, Epo-R, and GATA-1 mRNA expression evaluated in differentiating erythroid HPCs transduced with PilRES-GFP (Pi) or PilRESGFP/Ets-1 (Ets-1). S26 was used for normalization. Ets-1 mRNA was undetectable in Pi transduced cells since a lower number of PCR cycles was performed to avoid signal excess in Ets-1 samples. K562 erythroleukemia cell line was the internal positive control. (e) Real-time RT-PCR analysis of GATA-2 expression in erythroid differentiating HPCs transduced with Pi or Ets-1. GAPDH endogenous control was used for normalization. (f) A representative Western blot analysis of Pi or Ets-1 E cells at day 9 of culture performed with anti-Ets-1 and anti-GATA-2 antibodies. The immunodetection of actin was performed to control equal loading. RT-PCR and Western blot assays were reproducible over three experiments within cells with similar transduction efficiency 

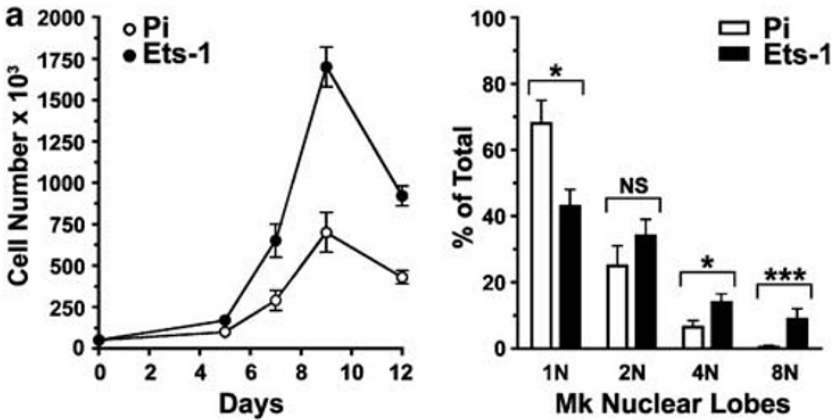

b

b d5

d7

d10
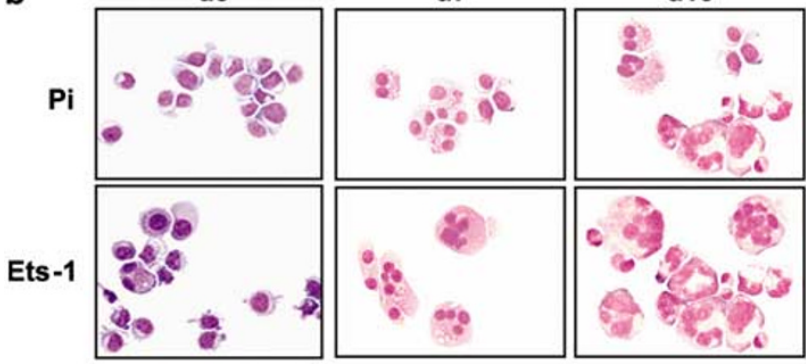

C
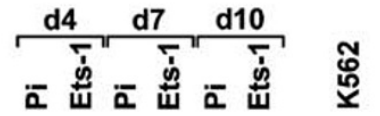

S26

Ets-1

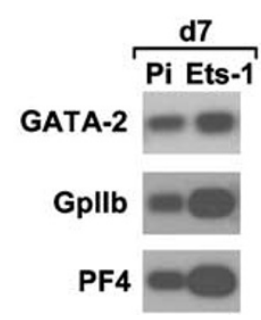

Figure 6 Effects of Ets-1 overexpression on MK differentiation. (a) Growth curve (left) and number of nuclear lobes per cell at day 10 of culture (right) of HPCs transduced with PilRES-GFP (Pi) or PilRES-GFP/Ets-1 (Ets-1) and grown in MK unilineage culture. Mean \pm S.E.M. values are representative of three independent experiments; ${ }^{*} P<0.05$; ${ }^{* * \star} P<0.001$. (b) Representative morphological analysis of MK differentiating HPCs transduced with Pi or Ets-1 (original magnification $\times 630$ ). (c) (Left) Semiquantitative RT-PCR analysis of Ets-1 in unilineage MK culture from HPCs transduced with PilRES-GFP (Pi) or PilRESGFP/Ets-1 at different days of culture. S26 was used for normalization and K562 erythroleukemia cell line was the internal positive control. (Right) Expression of relevant MK genes analyzed in the same culture at day 7. A representative experiment of three independent experiments is shown

as GATA-2, EpoR, and GATA-1. In Ets-1 overexpressing erythroid cells GATA-2 was upregulated, whereas GATA-1 and EpoR were downregulated (Figure 5d). GATA-2 upmodulation in Ets-1 overexpressing cells was confirmed by realtime RT-PCR (Figure 5e). Whole-cell lysates from either PilRES-GFP/Ets-1 or backbone control vector transduced cells (day 9), were examined by Western blot. The membrane was first probed with anti-Ets-1, then with anti-GATA-2 and anti-actin antibodies. As shown in Figure $5 f$, in Ets-1 overexpressing cells, an upregulation of GATA-2 protein of about two-fold with respect to control cells, was detected.

The analysis of MK cells overexpressing Ets-1 showed conversely a higher rate of proliferation (Figure 6a), a larger size and more nuclear lobes compared to control MK cultures (Figure $6 \mathrm{a}$ and $\mathrm{b}$ ), indicating that Ets-1 stimulates MK differentiation. Owing to the limited number of MK cells available, we analyzed the expression levels of a set of genes known to be involved in MK differentiation only by semiquantitative RT-PCR. In Ets-1 transduced MK cells GATA-2, GPIlb, and PF4 were upmodulated (Figure 6c). These results indicate that enforced expression of Ets-1 blocks erythroid maturation and promotes MK differentiation; the same results suggest that this effect may be mediated by GATA-2 upregulation.

\section{Ets-1 binds to Ets sites on the GATA-2 promoter}

We next investigated whether GATA-2 could be a direct target gene of Ets-1. We searched upstream of the transcription start site for sequence motifs which resembled the Ets-1 preferred consensus binding site. ${ }^{3}$ Two sites, EBS1 $(-819 /-853)$ and EBS2 $(-1248 /-1280)$ were identified and assessed by electrophoretic-mobility shift assays (EMSA). Both EBS1 and EBS2 reacted with nuclear extracts prepared from both $E$ and MK cells to form two complexes (I-II) in EMSA (Figure 7a, lanes 1 and 11; data not shown). Both complexes were competed by the addition of a cold oligonucleotide excess (lane 2) but not by oligonucleotide carrying mutations within the Ets site (EBS1 mt, lane 3). Incubation of erythroid cell extracts with labeled EBS1 mt resulted in loss of complex I formation (lanes 6 and 7) and in a decrease of complex II binding (lane 6). The addition of an anti-Ets-1 antibody, reacting against the DNA binding domain, resulted in the selective elimination of complex I both in E (lane 4) and Mk extracts (lane 12), confirming the presence of the Ets-1 protein within complex I. Anti-Fli-1 antibody (another member of the Ets gene family) or a preimmune serum did not affect complex formation in both cell extracts (lane 5 and data not shown). The addition of the anti-Ets-1 antibody caused an enhancement of complex II both with EBS1 wild-type (lanes 4 and 12) and EBS1 mt oligonucleotides (lane 7), suggesting that additional binding factor(s) within $\mathrm{E}$ and MK cells are capable to interact with the EBS1 site. Further work will be required to characterize this binding activity. In addition, the decrease of Ets-1 during erythroid differentiation was confirmed by EMSA. As shown in Figure 7a, Ets- 1 binding activity was downmodulated throughout the erythroid maturation process (lanes 8-10), while it was constant during MK differentiation (lanes 11 and 13).

\section{Activation of GATA-2 promoter by Ets-1}

To further examine the regulation of GATA-2 gene expression by Ets- 1 a $2.8 \mathrm{~Kb}$ fragment $(-2.8 \mathrm{~Kb} /+1)$ containing both EBS1 and EBS2 was cloned in a luciferase reporter vector (EBS2-EBS1-luc). The upstream region of the GATA-2 promoter containing the EBS2 was successively deleted using restriction enzymes to obtain a promoter region spanning from $-1.2 \mathrm{~Kb}$ to +1 and containing only the EBS1 (EBS1-luc). A construct containing the promoter region from $-0.7 \mathrm{~Kb}$ to +1 with both EBS1 and EBS2 sites deleted was also generated ( $\Delta \Delta$-luc). Each construct was cotransfected with either an expression plasmid encoding Ets-1 (pcDNA/ Ets-1) or an empty vector (pcDNA) in FLC cells. After $48 \mathrm{~h}$ of DMSO treatment, culture lysates were tested for luciferase activity. The activity of the EBS2-EBS1-luc and EBS1-luc reporter constructs increased respectively of 3- and 2.3-folds 


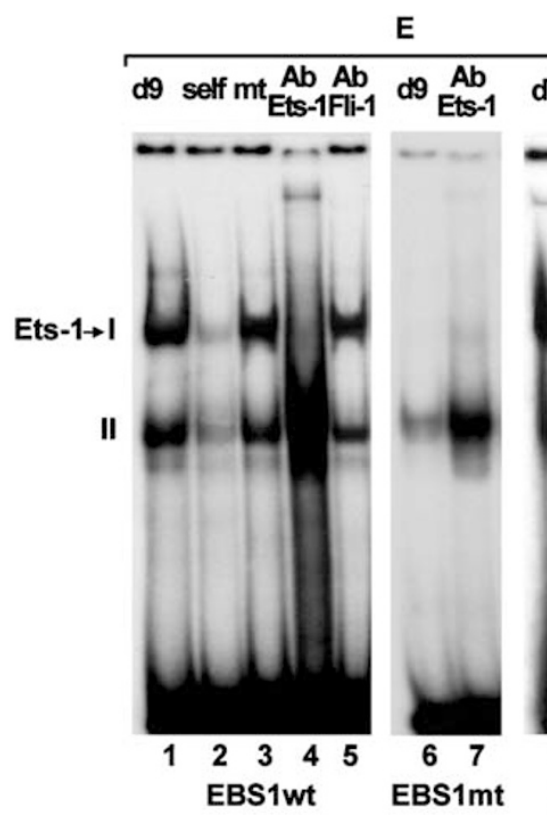

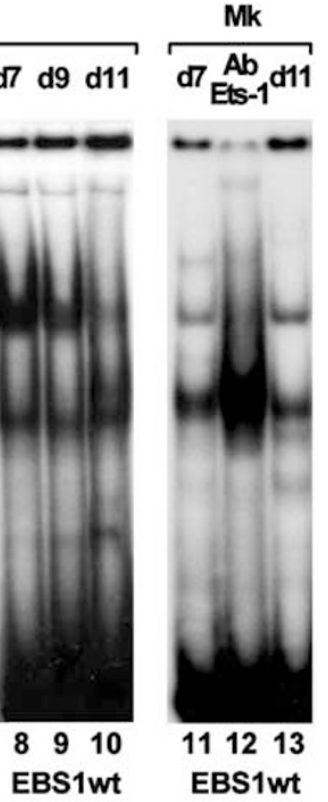

b

Fold of induction

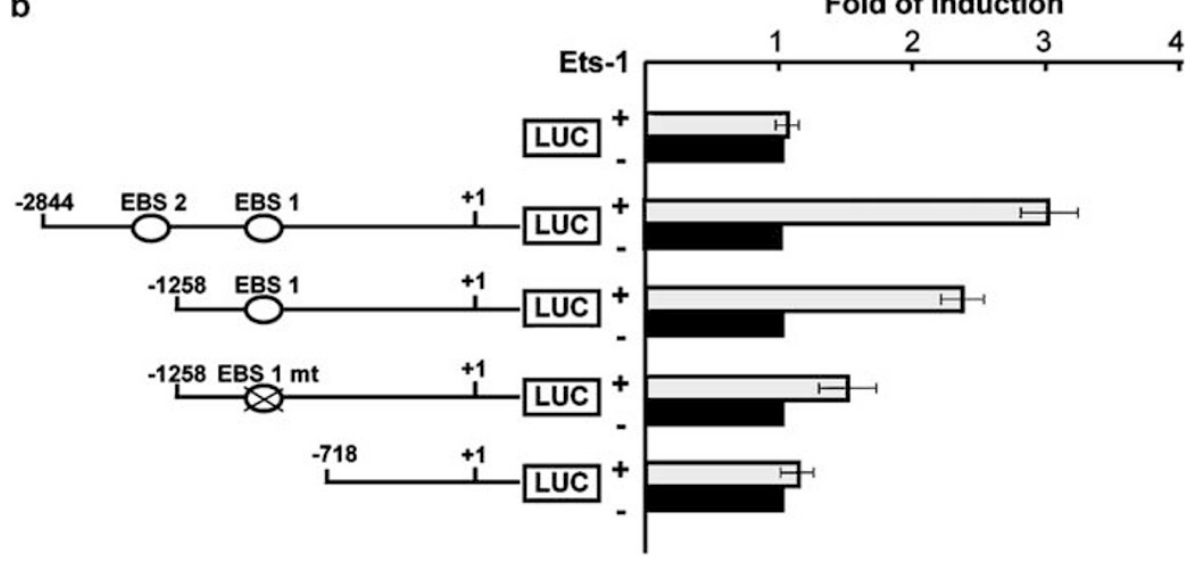

C

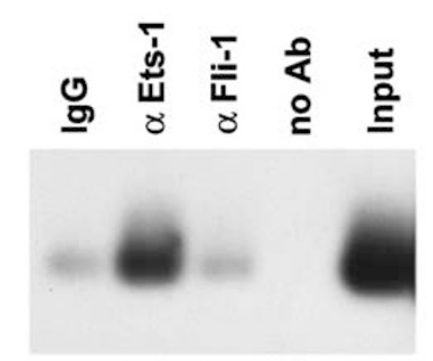

\section{GATA-2 promoter}

Figure 7 Ets-1 binding to the GATA-2 promoter in vitro and in vivo. (a) Nuclear extracts from human erythroblasts (8 $\mu \mathrm{g}$ ) (lanes 1-10) were incubated with a labeled oligonucleotide containing an Ets site in the GATA-2 promoter (EBS1wt-819-853) in the absence (lane 1) or presence of 200-fold molar excess of wild-type (lane 2) or mutated (lane 3) cold DNA competitors. Where indicated anti-Ets-1 or anti-Fli-1 antibodies were added to the reaction mixture. As control, nuclear extracts were incubated with a labeled mutated EBS1-GATA-2 probe (EBS1mt) (lanes 6 and 7). Nuclear extracts at different days of culture incubated with labeled EBS1wt probe (lanes 8-10). Nuclear extracts from primary human megakaryocytes at different days of cultures (lanes 11-13) incubated with labeled EBS1wt oligonucleotide. Where indicated, anti-Ets-1 antibody was added to the reaction. Owing to the limited number of available MK cells, EMSA was performed with half amount of nuclear extracts $(4 \mu \mathrm{g}$ instead of $8 \mu \mathrm{g}$ used for erythroid cells). (b) FLC cells were transiently cotransfected with the reporter vectors (EBS2-EBS1-luc, EBS1-luc, EBS1 mt-luc, $\Delta \Delta$-luc), with pcDNA/Ets-1 $(+)$ or with pcDNA (-) and with TK-Renilla normalizator vector. After $48 \mathrm{~h}$ of $1.5 \%$ DMSO treatment luciferase activity was determined. Each histogram represents the average - fold of induction of normalized values + S.D. of three separate experiments. (c) In ChIP assay the chemically crosslinked and fragmented chromatin was precipitated by antibodies against Ets-1 and Fli-1. As negative control chromatin immunoprecipitation was performed either with no antibody or with lgG. The presence of GATA-2 within those final precipitates and input lysates was examined by PCR amplification of a specific 399 bp sequence spanning EBS1 
in FLC cells cotransfected with Ets-1 expression plasmid as compared with the control vector alone (Figure $7 \mathrm{~b}$ ). When both the EBS1 and EBS2 sites were deleted, activation of GATA-2 transcription by Ets-1 was almost completely abolished. Moreover, deletion of the upstream region containing EBS2 resulted in a $25 \%$ decrease in promoter transactivation suggesting that Ets-1 transactivates GATA-2 preferentially through the region containing EBS1. To analyze EBS1 contribution the GGA core was mutated by site directed mutagenesis (EBS1 mt-luc), cotransfected with either the pcDNA/Ets-1 or pcDNA vectors in FLC cells and treated with $1.5 \%$ DMSO. As shown in Figure $7 \mathrm{~b}$ disruption of EBS1 resulted in a further $40 \%$ decrease in promoter transactivation suggesting that Ets-1 could interact with other GGA motifs located in this promoter region (from -1.2 to $-0.7 \mathrm{~kb}$ ).

\section{GATA-2 promoter is bound by Ets-1 in vivo}

To demonstrate that Ets-1 binds in vivo to the endogenous GATA-2 promoter, we performed ChIP assay using crosslinked protein-DNA complexes prepared from erythroid cells at day 8 of culture (basophilic erythroblasts). The immunoprecipitated obtained with an anti Ets-1 antibody were analyzed by PCR using primers specifically designed to amplify a GATA-2 promoter region encompassing the EBS1 site. As shown in Figure 7c the antibody against Ets-1 effectively precipitated chromatin fragments containing GATA-2 promoter, clearly indicating that Ets-1 plays a functional role in the regulation of GATA-2 expression.

\section{Discussion}

We have analyzed the role of Ets-1 during erythroid and MK differentiation. Ets-1 expression is mantained during all stages of megakaryocytopoiesis and its overexpression promotes MK maturation. Conversely, during erythroid differentiation Ets-1 is downmodulated and progressively excluded from the nucleus. Moreover, enforced expression of Ets-1 in erythroid cells blocks their maturation at the polychromatophilic stage.

Our results indicate that the mechanism of nuclear exclusion of Ets-1 is based on active nuclear export mediated by a leucine-rich NES. In order to be selectively translocated, proteins must contain a defined export signal, which is recognized by specific nuclear receptors. Proteins containing a NES, represented by a short stretch of leucine or hydrophobic residues, are exported from the nucleus through CRM1/exportin1 pathway. ${ }^{24}$ LMB is a specific inhibitor of the nuclear export receptor CRM1/exportin1. ${ }^{24}$ We found that Ets-1 nuclear export was blocked by LMB. When we examined the peptide sequence of Ets-1 we found a stretch of residues located in the pointed domain of the protein, resembling the Rev-like NES. We show that this sequence represents a functional NES since it is able to drive nuclear exclusion when fused to the GFP reporter protein. To date only two members of the Ets family, $\mathrm{TEL}^{26}$ and $\mathrm{NET}^{25}$ repressors have been shown to be exported from the nucleus via the CRM1/exportin1 pathway, and the functional NES of NET was found to be located in the Ets domain of the protein.
Several Ets proteins, including Ets-1, contain NES-like sequences within the Ets domain, but none of them was found to be able to mediate nuclear export. ${ }^{25}$ Ets-1 nuclear exclusion appears to be specifically activated during erythroid differentiation. Additional studies will be required to establish a link among Ets-1 nuclear export, putative protein modifications required to trigger nuclear export, cell lineage and stage of differentiation.

During MK differentiation, on the contrary, Ets- 1 is retained in the nucleus up to the end of maturation. We found that its overexpression accelerates MK differentiation giving rise to large polyploid cells and upregulating GATA-2 and megakaryocyte-specific genes (i.e. PF4, GPIIb). We observed an increased expression of the GATA-2 transcription factor also in erythroid cells overexpressing Ets-1.

GATA-2 plays a relevant role both in the hematopoietic stem/progenitor cell compartment and in hematopoietic lineage commitment. GATA-2 is expressed in MK and in immature $E$ cells. In erythroid cells a decrease of GATA-2 gene expression was shown to be required for differentiation, ${ }^{17,19,20}$ as its overexpression in hematopoietic cells inhibits erythroid maturation. ${ }^{19-21}$ Conversely, GATA-2 remains expressed at high level during all maturation stages of primary human MK cells, ${ }^{14}$ and our unpublished observation. Although the functional contribution of GATA-2 in normal megakaryocyte development remains to be determined, its overexpression in hematopoietic cell lines was shown to induce MK differentiation. ${ }^{19,22}$

This differential regulation of GATA-2 in the erythroid and MK lineages, which parallels Ets-1 expression, prompted us to examine the effects of Ets-1 on the transcription of GATA-2. Surprisingly, little is known on GATA-2 transcriptional regulation. Previous studies indicated that the GATA-2 promoter contains several GGA motifs, the core recognition sequence for the Ets factors ${ }^{27}$ suggesting that these proteins could be involved in GATA-2 regulation. EMSA, transfection, and ChIP experiments demonstrated that Ets- 1 binds in vitro and in vivo to the GATA-2 promoter suggesting that it has a functional role in the regulation of GATA-2 expression. In the hematopoietic system Ets-1 and GATA-2 are coexpressed in the yolk sac, ${ }^{17,28}$ and in hematopoietic progenitors. ${ }^{17}$ Interestingly, in erythroid cells GATA-2 was shown to disappear at the polychromatophilic stage ${ }^{29}$ concomitantly with the clearing of the Ets-1 protein. Thus, GATA-2 and Ets-1 expression pattern and function are consistent with the hypothesis that these factors participate in the same regulatory network during erythroid and MK maturation.

Ets-1 overexpressing erythroid cells showed, besides an increase of GATA-2 expression, also a more immature phenotype associated with lower levels of EpoR and GATA1 mRNA. It will be interesting to determine whether Ets-1 could also directly regulate EpoR and GATA-1 by binding to their promoters since the GATA-1 promoter contains several EBSs. Alternatively, Ets-1 could indirectly downmodulate EpoR and GATA- 1 by activating GATA-2 which in turn inhibits EPO-dependent erythroid differentiation. ${ }^{30}$ During megakaryopoiesis Ets-1 directly regulates the expression of genes relevant for platelet function such as the thrombopoietin receptor, ${ }^{31}$ the platelet factor $4(P F 4)^{32}$ and glycoprotein IIb $(G P I l b) .{ }^{33}$ Thus, Ets-1 could play a relevant role during MK 
differentiation regulating directly important MK-specific genes and indirectly sustaining GATA-2 gene expression. In view of the close relationship between erythroid and MK pathways, these observations suggest that Ets-1 could control both immature $\mathrm{E}$ and $\mathrm{MK}$ progenitor cells. During erythroid differentiation Ets-1 has to be inactivated for proper red blood cells maturation, whereas it remains expressed at high levels during MK differentiation, since it positively controls the expression of relevant MK genes.

Taken together our data indicate that during hematopoiesis Ets-1 behavior is similar to that of Fli-1, another member of the Ets gene family. In vitro differentiation studies have shown that in human hematopoietic cell lines, Fli-1 expression promotes $\mathrm{MK}^{34}$ and suppresses erythroid differentiation. ${ }^{35,36}$ The patterns of expression of Ets-1 and Fli- 1 were shown to be similar, ${ }^{28,37}$ and we found that during 'in vitro' erythroid and MK differentiation, Fli-1 expression profile was superimposable to that of Ets-1 (our unpublished data). Interestingly, the Ets-1 and Fli-1 genes are physically linked, located within $200 \mathrm{~kb}$ on human chromosome 11. Congenital MK maturation defects and a mild hemorrhagic phenotype have been found in individuals heterozygous for a chromosomal deletion, which removes both Fli-1 and Ets-1. ${ }^{38}$ This observation is compatible with the hypothesis that Ets-1 may have overlapping or cooperative functions with Fli-1 and both genes may participate in the divergence of the MK from the erythroid lineage.

\section{Materials and Methods}

\section{HPCs purification, infection and unilineage cultures}

Adult PB, obtained from healthy donors after informed consent, was collected in citrate/phosphate/destrose/adenine (CPDA-1) anticoagulant. A buffy coat was obtained by centrifugation at 1400 r.p.m. for $20 \mathrm{~min}$ at room temperature. Low-density mononuclear cells (less than $1077 \mathrm{~g} / \mathrm{ml}$ ) were isolated by Ficoll-Hypaque density gradient centrifugation. CD34 ${ }^{+}$ HPCs were then purified using the MiniMACS CD34 isolation system (Miltenyi Biotech, Bergisch Gladbach, Germany) according to the manifacturer's instructions. Purified cells were more than $90 \% \mathrm{CD}^{+} 4^{+}$, as evaluated by fluorescence-activated cell-sorting (FACS) analysis. Before infection $\mathrm{CD} 34^{+}$cells were induced to proliferate for $48 \mathrm{~h}$ in fetal calf serum free $\left(\mathrm{FCS}^{-}\right)$liquid culture $\left(5 \times 10^{4}\right.$ cells $\left./ \mathrm{ml}\right)$ supplemented with interleukin-3 (IL-3 $10 \mathrm{U} / \mathrm{ml}$ Roche, Basel, Switzerland), Kit ligand (KL $10 \mathrm{ng} / \mathrm{ml})$, interleukin-6 (IL-6 $10 \mathrm{ng} / \mathrm{ml})$, FLT-3 ligand (FL $100 \mathrm{ng} / \mathrm{ml})$, basic fibroblast growth factor (bFGF $100 \mathrm{ng} / \mathrm{ml}$ ) (Prepotech, London, UK) in a fully humidified atmosphere of $5 \% \mathrm{CO}_{2} / 5 \% \mathrm{O}_{2} / 90 \% \mathrm{~N}_{2}$. Amphotropic packaging cell line Phoenix was transfected by calcium-phosphate/ chloroquine method with the retroviral vector $\mathrm{Pi}^{39}$ containing Ets- 1 cDNA linked to the GFP gene and with the envelope plasmid containing the G-glycoprotein of vescicular stomatitis virus (VSV-G), to overcome the restricted host-cell range of the retroviral vector. CD34 ${ }^{+}$cells were subjected to five infection cycles. For each cycle HPCs were suspended at $5 \times 10^{4} / \mathrm{ml}$ in retroviral supernatant $\left(>10^{6} \mathrm{PFU} / \mathrm{ml}\right)$ in presence of polybrene $(4 \mu \mathrm{g} / \mathrm{ml})$, cycling growth factors (FL $100 \mathrm{ng} / \mathrm{ml}, \mathrm{KL} 1 \mathrm{ng} / \mathrm{ml}$ and IL-3 $10 \mathrm{U} / \mathrm{ml}$ ) and centrifuged at 1800 r.p.m. for $45 \mathrm{~min}$ at $32^{\circ} \mathrm{C}$. GFPpositive cells, separated by flow cytometry using a FACS-Vantage (BD Biosciences, San Jose, CA, USA), were induced either to unilineage erythroid or MK differentiation. Briefly, GFP-positive cells were grown in
FCS liquid culture $\left(5 \times 10^{4}\right.$ cells $\left./ \mathrm{ml}\right)$ supplemented with very low doses of IL-3 $(0.01 \mathrm{U} / \mathrm{ml})$ and granulo-monocytes colony stimulating factor (GMCSF $0.001 \mathrm{ng} / \mathrm{ml}$ ) and plateau level of erythropoietin (Epo $3 \mathrm{U} / \mathrm{ml}$ ) for erythroid culture or supplemented with thrombopoietin (TPO $100 \mathrm{ng} / \mathrm{ml}$ ) for MK culture. Cells were counted and analyzed for morphology on MayGrünwald-Giemsa stained cytospin slides every $48 \mathrm{~h}$.

\section{Plasmids}

Ets-1 cDNA was subcloned into the Pi-IRES-GFP vector under the transcriptional control of the $5^{\prime}$ long terminal repeat (LTR) ${ }^{39}$ In brief, this retroviral vector contains the full-length Moloney LTRs, while the original cytomegalovirus (CMV)-GFP cassette was substituted by a viral IRESGFP which is the most efficient tool for coexpressing two genes from a single provirus.

For transient transfection assays Ets-1 cDNA was also subcloned in pcDNA3 expression vector (Invitrogen, Carlsbad, CA, USA). The p2 $\times$ GFP-NLS and p2 $\times$ GFP-NLS-NES-Rev were provided by $\mathrm{V}$. Zappavigna. ${ }^{40}$ Ets-1 cDNA fragment (amino-acids 87-156), containing the putative NES sequence (amino-acids 121-131), was subcloned in frame with the GFP gene in the $\mathrm{p} 2 \times$ GFP-NLS plasmid. To generate the Ets-1-GFP fusion protein, Ets-1 cDNA was subcloned in a pcDNA3 vector in frame with the GFP. The mutations in both constructs, introduced by PCR mutagenesis using the Quik-Change Site-Directed Mutagenesis kit (Stratagene, La Jolla, CA, USA), were confirmed by DNA sequencing. The primer used to introduce the mutations was:

L129A-I131N 5'-TTATGGGAACATgcAGAGAaCCTGCAGAAAGAGG ATG-3'.

The GATA-2 promoter sequence from -2844 bps to +1 , was amplified by PCR, sequenced and cloned into pGL3-basic vector (Promega, Madison, WI, USA) (EBS2-EBS1-luc). To generate EBS1-luc plasmid, the $-2.8 \mathrm{~kb}$ construct was digested with Aatll and Kpnl and religated. The double-deleted construct $(\Delta \Delta$-luc) was obtained by Pvull restriction enzyme. The plasmid carrying the mutated GGA box (EBS1 mtluc) was prepared using the Quik-Change Site-Directed Mutagenesis kit. The primer used to introduce the mutations was: 5'-GGGGAGCACTgat AtGTGACTTAGAAGACG-3'. The mutated region was confirmed by sequencing.

\section{Cell cultures, transfections, treatments and reporter gene assays}

FLCs, clone $745-A,{ }^{36}$ a mouse erythroleukemic cell line, were grown in RPMI 1640 medium supplemented with 5\% FCS and antibiotics. Cells seeded at $5 \times 10^{5} / \mathrm{ml}$, were transfected using FuGENE 6 transfection reagent (Roche) according to the manufacturer's instructions and treated with $1.5 \%$ DMSO (dimethylsulfoxide) for $48 \mathrm{~h}$. LMB treatment was performed with $250 \mathrm{nM}$ for $4 \mathrm{~h}$. For luciferase assay cells were collected and lysed according to the manufacturer's protocol (Promega). Luciferase activity of each sample was normalized with respect to Renilla activity (TK-Renilla).

\section{Immunolocalization of Ets-1 in erythrocytes and megakaryocytes}

Cellular localization of Ets-1 was investigated by confocal microscopy after immunofluorescence labeling. Cytospin preparations of erythroblasts and megakaryocytes prepared at low speed (5 min at 400 r.p.m.) on polylysinated slides were fixed $15 \mathrm{~min}$ at room temperature with $4 \%$ 
buffered paraformaldehyde, then permeabilized $15 \mathrm{~min}$ at room temperature by incubation with $0.1 \%$ Triton X-100 in PBS/BSA. After washing, the cells were incubated $1 \mathrm{~h}$ at $4^{\circ} \mathrm{C}$ with $5 \mu \mathrm{g}$ anti-Ets-1 (BD Biosciences) or $1 \mu \mathrm{g}$ anti-GATA-1 (N-1, Santa Cruz Biotecnology, Santa Cruz, CA, USA) antibodies. After extensive washing cells were incubated with TRITClabeled affinity purified rabbit anti-mouse IgGs (Dako, Golstrup, Denmark) for Ets-1 or FITC-labeled affinity purified rabbit anti-rat IgGs (Dako) for GATA-1 and analyzed by confocal microscopy using an inverted fluorescence microscope (Olympus, Melville, NY, USA) equipped with an APO-PLAN $63 \times 1.4$. LMB treatment of erythroid cells was performed with $250 \mathrm{nM}$ for $4 \mathrm{~h}$.

\section{RNA Extraction and Analysis}

Total RNAs were extracted by the guanidinium isothiocyanate-CsCl method and reverse transcribed by Moloney murine leukemia virus reverse transcriptase (Invitrogen) with oligo(dT). The RT-PCR were normalized for S26 ribosomal protein.

The sequences of the oligonucleotide primers used for RT-PCR were:

S26 5'-GCCTCCAAGATGACAAAG-3', 5'-CCAGAGAATAGCCTGT CT-3'; Ets-1 5'-CAGACAACATGTGCATGGG-3', 5'-CCACCTCATCT GGGTCAGA-3';

GATA-2 5'-TCCAGCTTCACCCCTAAGCAG-3', 5'-GCATGCACTTT GACAGCTCC-3'; GATA-1 5'-TTAGCCACCTCATGCCTT-3', 5'-GAG ACTTGGGTTGTCCAG-3';

EpoR 5'-GTATCATGGACCACCTCG-3', 5'-CGGATGTGAGACGTCA TG-3';

GPIIb(CD41) 5'-GACTGTGAATGGTCTTCACCTC-3', 5'-ACACGTTG AACCATGCGTGCGA-3'; PF4 5'-GCGCTGAAGGTGAAGAAGATG-3', 5'-GCACACACGTAGGCAGCTAGT-3'.

Samples were electrophoresed in 1.5\% agarose gel, transferred onto Hybond-N (Amersham Pharmacia Biotech, Uppsala, Sweden) filter and hybridized with an internal oligomer probe.

Real-Time RT-PCR analysis was performed using an ABI Prism 7700 Sequence Detector (Applied Biosystems, Foster City, CA, USA). Primers and probe for GATA-2 gene were designed using the Primer Express software (Applied Biosystems). The sequences of the primers pair and fluorogenic Taqman probe were $5^{\prime}$-CTCCCACCTTTTCGGCTT-3' ${ }^{\prime}, 5^{\prime}$ CGTGGTGCTAGGGTCAGGA-3', 5'-FAM-CACCCACGCCACCCAAAG AAGTG-TAMRA-3'.

\section{Western blot assay}

To prepare cytoplasmic and nuclear extracts the cells were washed with PBS and resuspended in buffer A (10 mM HEPES pH 7.9, $1.5 \mathrm{mM} \mathrm{MgCl}_{2}$, $10 \mathrm{mM} \mathrm{KCl}$ and protease inhibitors) incubated $15 \mathrm{~min}$ on ice and centrifuged at 10000 r.p.m. for $3 \mathrm{~min}$ to obtain cytoplasmic protein in the supernatant. The nuclear pellet was lysed in buffer $\mathrm{C}(20 \mathrm{mM}$ HEPES $\mathrm{pH}$ $7.9,25 \%$ (v/v) glycerol, $420 \mathrm{mM} \mathrm{NaCl}, 1.5 \mathrm{mM} \mathrm{MgCl}_{2}, 0.2 \mathrm{mM}$ EDTA and protease inhibitors). Of cell extracts, $10 \mu \mathrm{g}$, were loaded onto a $8 \%$ SDSPAGE (sodium dodecyl sulfate-polyacrylamide gel electrophoresis), transferred onto Hybond-C (Amersham) paper, incubated with monoclonal anti-Ets-1 (BD Biosciences), anti- $\alpha$ tubulin, anti-nucleolin (Santa Cruz Biotechnology), anti-GFP (BD Biosciences), anti-actin (Oncogene Research, San Diego, CA, USA), anti-GATA-2 (provided by S. Orkin) antibodies and detected using ECL detection kit (Pierce, Rockford, IL, USA).

\section{DNA electrophoretic mobility shift assay (EMSA)}

Nuclear extracts, prepared as described above, were added to binding reaction containing end-labeled double-stranded oligonucleotide in binding buffer $(75 \mathrm{mM} \mathrm{KCl}, 20 \mathrm{mM}$ Tris- $\mathrm{HCl} \mathrm{pH} 7.5,1 \mathrm{mM}$ DTT), $1 \mu \mathrm{g}$ BSA, $14 \%$ (v/v) glycerol, $0.5 \mu \mathrm{g}$ poly(dl)-poly(dC). Samples were electrophoresed in $5 \%$ polyacrylamide gel in $0.5 \times$ TBE buffer for $2 \mathrm{~h}$ at $200 \mathrm{~V}$ at $16^{\circ} \mathrm{C}$. For supershift analysis, anti-Ets-1 (Chemicon International, Temecula, CA, USA) or anti-Fli-1 (BD Biosciences) antibodies were added to the reaction. 200-fold molar excess of cold oligonucleotide was used for competitions. The oligonucleotides used were:

\section{EBS1-GATA-2: (-819/-853) 5'-GAGTGGGGAGCACTTCCAGGTGA CTTAGAAGACG-3' \\ EBS1 mt-GATA-2: (-819/-853) 5'-GAGTGGGGAGCACTgatAtGTGA CTTAGAAGACG-3'}

\section{Chromatin immunoprecipitation assay}

Chromatin immunoprecipitation (ChIP) assay was performed according to Upstate Biotechnology protocol (Lake Placid, NY, USA). Briefly $3.5 \times 10^{6}$ human erythroblasts at day 8 of culture were crosslinked in vivo, lysed and immediately sonicated. Chromatin fragments were immunoprecipitated either with $4 \mu \mathrm{g}$ of anti-Ets-1 (N-1, Santa Cruz Biotecnology) or with $4 \mu \mathrm{g}$ of anti-Fli-1 (BD Biosciences) antibodies, and amplified by PCR for 30 cycles using primers from -799 to $-1198 \mathrm{bp}$ GATA-2 promoter (5'CCTCCAGTTACCCAATTACCGACTGTC-3'; 5'-AGGCGGTGGTCAGA GGTCTCCG-3'; probe 5'-GAGTGGGGAGCACTTCCAGGTGACTTAG AAGACG-3').

\section{Acknowledgements}

This work was supported by institute fund from the Istituto Superiore di Sanità and Grant from the Italy-USA program on 'Therapy of Tumors'. The authors gratefully acknowledge Stuart Orkin (Children' Hospital, Boston, MA) and Vincenzo Zappavigna (University of Modena and Reggio Emilia, Modena, Italy) for providing reagents, Ruggero De Maria for critically reading the manuscript, Mariangela Fontana and Monica Blasi for editorial assistance and Alfonso Zito and Giuseppe Loreto for graphics.

\section{References}

1. Oikawa $T$ and Yamada $T$ (2003) Molecular biology of the Ets family of transcription factors. Gene 303: 11-34

2. Papas TS, Bhat NK, Spyropoulos DD, Mjaatvedt AE, Vournakis J, Seth A and Watson DK (1997) Functional relationships among ETS gene family members. Leukemia 11: 557-566

3. Watson DK and Seth A (2000) Ets Gene Family. Oncogene Rev. 19 (55) review issue 5, Macmillan Publishers Ltd

4. Hahn SL and Wasylyk B (1994) The oncoprotein v-ETS is less selective in DNA binding than C-ETS-1 due to the C-terminal sequence change. Oncogene 9: 2499-2512

5. Cowley DO and Graves BJ (2000) Phosphorylation represses Ets-1 DNA binding by reinforcing autoinhibition. Genes Dev. 14: 366-376

6. Seidel JJ and Graves BJ (2002) An ERK2 docking site in the Pointed domain distinguishes a subset of ETS transcription factors. Genes Dev. 16: 127-137

7. Lelievre E, Lionneton F, Soncin F and Vandenbunder B (2001) The Ets family contains transcriptional activators and repressors involved in angiogenesis. Int. J. Biochem. Cell Biol. 4: 391-407 
8. Bories JC, Willerford DM, Grevin D, Davidson L, Camus A, Martin P, Stehelin D and Alt FW (1995) Increased T-cell apoptosis and terminal B-cell differentiation induced by inactivation of the Ets-1 proto-oncogene. Nature 377: 635-638

9. Barton K, Muthusamy N, Fischer C, Ting CN, Walunas TL, Lanier LL and Leiden JM (1998) The Ets-1 transcription factor is required for the development of natural killer cells in mice. Immunity 9: 555-563

10. Sieweke MH, Tekotte H, Frampton J and Graf T (1996) MafB is an interaction partner and repressor of Ets-1 that inhibits erythroid differentiation. Cell 85: 49-60

11. Clausen PA, Athanasiou M, Chen Z, Dunn KJ, Zhang Q, Lautenberger JA, Mavrothalassitis $G$ and Blair DG (1997) Ets-1 induces increased expression of erythroid markers in the pluripotent erythroleukemic cell lines K562 and HEL. Leukemia 11: 1224-1233

12. Kraut N, Frampton J, McNagny KM and Graf T (1994) A functional ETS DNAbinding domain is required to maintain multipotency of hematopoietic progenitors transformed by Myb-Ets. Genes Dev. 8: 33-44

13. Rossi F, McNagny KM, Logie C, Stewart AF and Graf T (1996) Excision of Ets by an inducible site-specific recombinase causes differentiation of Myb-Etstransformed hematopoietic progenitors. Curr. Biol. 6: 866-872

14. Teuri K, Takashi Y, Kitazawa J, Toki T, Yokoyama M and Ito E (2000) Expression of transcription factors during megakaryocytic differentiation of CD34+ cells from human cord blood induced by thrombopoietin. Tohoku. J. Exp. Med. 192: 259-273

15. Shivdasani RA (2001) Molecular and transcriptional regulation of megakaryocyte differentiation. Stem Cell 19: 397-407

16. Tsai FY, Keller G, Kuo FC, Weiss M, Chen J, Rosenblatt M, Alt FW and Orkin $\mathrm{SH}$ (1994) An early hematopoietic defect in mice lacking the transcription factor GATA-2. Nature 371: 221-226

17. Tsai FY and Orkin SH (1997) Transcription factor GATA-2 is required for proliferation/survival of early hematopoietic cells and mast cell formation, but not for erythroid and myeloid terminal differentiation. Blood 89: 3636-3643

18. Shivdasani RA and Orkin SH (1996) The transcriptional control of hematopoiesis. Blood 87: 4025-4039

19. Ikonomi $P$, Rivera $C E$, Riordan $M$, Washington $G$, Schechter $A N$ and Noguchi CT (2000) Overexpression of GATA-2 inhibits erythroid and promotes megakaryocyte differentiation. Exp. Hematology 28: 1423-1431

20. Kamesaki H, Michaud GY, Irving SG, Suwabe N, Kamesaki S, Okuma M and Cossman J (1996) TPA-induced arrest of erythroid differentiation is coupled with downregulation of GATA-1 and upregulation of GATA-2 in an erythroid cell line SAM-1. Blood 87: 999-1005

21. Ohneda $K$ and Yamamoto $M$ (2002) Roles of hematopoietic transcription factors GATA-1 and GATA-2 in the development of red blood cell lineage. Acta Haematol. 108: 237-245

22. Visvader JE, Crossley M, Hill J, Orkin SH and Adams JM (1995) The C-terminal zinc finger of GATA-1 or GATA-2 is sufficient to induce megakaryocytic differentiation of an early myeloid cell line. Mol. Cell. Biol. 15: 634-641

23. Marziali G, Perrotti E, llari R, Lulli V, Coccia EM, Moret R, Kuhn LC, Testa U and Battistini A (2002) Role of Ets-1 in transcriptional regulation of transferrin receptor and erythroid differentiation. Oncogene 21: 7933-7944

24. Mattaj IW and Englmeier L (1998) Nucleocytoplasmic transport: the soluble phase. Annu. Rev. Biochem. 67: 265-306
25. Ducret C, Maira SM, Dierich A and Wasylyk B (1999) The Net repressor is regulated by nuclear export in response to anisomycin, UV, and heat shock. Mol. Cell. Biol. 19: 7076-7087

26. Wood LD, Irvin BJ, Nucifora G, Luce KS and Hiebert SW (2003) Small ubiquitinlike modifier conjugation regulates nuclear export of TEL, a putative tumor suppressor. Proc. Natl. Acad. Sci. 100: 3257-3262

27. Fleenor DE, Langdon SC, deCastro CM and Kaufman RE (1996) Comparison of human and Xenopus GATA-2 promoters. Gene 179: 219-223

28. Kola I, Brookes S, Green AR, Garber R, Tymms M, Papas TS and Seth A (1993) The ETS-1 transcription factor is widely expressed during murine embryo development and is associated with mesodermal cells involved in morphogenetic processes such as organ formation. Proc. Natl. Acad. Sci. 90: 7588-7592

29. Koury MJ, Sawyer ST and Brandt SJ (2002) New insights into erythropoiesis. Curr. Opin. Hematol. 9: 93-100

30. Imagawa S, Yamamoto M and Miura Y (1997) Negative regulation of the erythropoietin gene expression by the GATA transcription factors. Blood 4: 1430-1439

31. Deveaux S, Filipe A, Lemarchandel V, Ghysdael J, Romeo PH and Mignotte V (1996) Analysis of the thrombopoietin receptor (MPL) promoter implicates GATA and Ets proteins in the coregulation of megakaryocyte-specific genes. Blood 87: 4678-4685

32. Minami T, Tachibana K, Imanishi T and Doi T (1998) Both Ets-1 and GATA-1 are essential for positive regulation of platelet factor 4 gene expression. Eur. J. Biochem. 258: 879-889

33. Lemarchandel V, Ghysdael J, Mignotte V, Rahuel C and Romeo PH (1993) GATA and Ets cis-acting sequences mediate megakaryocyte-specific expression. Mol. Cell. Biol. 13: 668-676

34. Eisbacher M, Holmes ML, Newton A, Hogg PJ, Khachigian LM, Crossley M and Chong BH (2003) Protein-protein interaction between Fli-1 and GATA-1 mediates synergistic expression of megakaryocyte-specific genes through cooperative DNA binding. Mol. Cell. Biol. 23: 3427-3441

35. Pereira R, Quang CT, Lesault I, Dolznig H, Beug H and Ghysdael J (1999) FLI1 inhibits differentiation and induces proliferation of primary erythroblasts. Oncogene 18: 1597-1608

36. Starck J, Doubeikovski A, Sarrazin S, Gonnet C, Rao G, Skoultchi A, Godet J, Dusanter-Fourt I and Morle F (1999) Spi-1/PU.1 is a positive regulator of the Fli1 gene involved in inhibition of erythroid differentiation in Friend Erythroleukemic cell lines. Mol Cell Biol. 19: 121-135

37. Bhat NK, Fisher RJ, Fujiwara S, Ascione R and Papas TS (1987) Temporal and tissue-specific expression of mouse ets genes. Proc. Natl. Acad. Sci. 84 3161-3165

38. Breton-Gorius, J, Favier R, Guichard J, Cherif D, Berger R, Debili N, Vainchenker W and Douay L (1995) A new congenital dysmegakaryopoietic thrombocytopenia (Paris-Trousseau) associated with giant platelet alphagranules and chromosome 11 deletion at 11q23. Blood 85: 1805-1814

39. Coppola S, Narciso L, Feccia T, Bonci D, Calabrò L, Morsilli O, Gabbianelli M, De Maria R, Testa U and Peschle C (2005) Enforced expression of KDR receptor promotes proliferation, survival and megakaryocytic differentiation of TF1 progenitor cell line. Cell Death Differentiation X: 1-14

40. Kilstrup-Nielsen C, Alessio M and Zappavigna V (2003) PBX1 nuclear export is regulated independently of PBX-MEINOX interaction by PKA phosphorylation of the PBC-B domain. EMBO J. 22: 89-99 